\title{
Induction of Prostacyclin Biosynthesis Is Closely Associated with Increased Guanosine 3',5'-Cyclic Monophosphate Accumulation in Cultured Human Endothelium
}

\author{
Abigail F. Adams Brotherton \\ Cardiovascular Center and Division of Hematology-Oncology, Department of Medicine, University of Iowa, Iowa City, Iowa 52242
}

\begin{abstract}
Stimuli of prostacyclin (PGI $\mathbf{P}_{2}$ ) biosynthesis such as thrombin, bradykinin, histamine, and A23187 increase guanosine 3',5'-cyclic monophosphate (cyclic GMP) levels in primary monolayer cultures of human umbilical vein endothelium by about twofold. This effect is dependent on the presence of extracellular $\mathrm{Ca}^{2+}$. Increases of about tenfold are observed when cyclic GMP phosphodiesterase activity is inhibited, which suggests that the observed increases in cyclic GMP involve the activation of guanylate cyclase. Activation of guanylate cyclase appears to involve an early event in the induction of $\mathbf{P G I}_{2}$ biosynthesis, as neither arachidonic acid nor its metabolites stimulate cyclic GMP accumulation. Although activators of guanylate cyclase such as atriopeptin III, sodium nitroprusside, and tert-butylhydroperoxide increase cyclic GMP levels by 2-3-fold, they do not stimulate or modulate $\mathbf{P G I}_{2}$ production. We conclude that cyclic GMP does not play a primary role in mediating the induction or regulation of $\mathbf{P G I}_{2}$ biosynthesis in vascular endothelium.
\end{abstract}

\section{Introduction}

The interaction of extracellular messengers with specific cell surface receptors results in the formation of intracellular messengers that ultimately mediate cellular activation. Most tissues appear to possess two major classes of receptors for controlling cellular function and proliferation; one class triggers the production of cyclic AMP while the other induces inositol phospholipid turnover. It is now accepted that phosphatidylinositol breakdown constitutes an important part of the receptor mechanism involved in the elevation of cytosolic $\mathrm{Ca}^{2+}$ (reviewed in references $1-4)$. $\mathrm{Ca}^{2+}$ mobilization by physiological stimuli appears to be closely associated with the receptor-activated hydrolysis of phosphatidylinositol 4,5-bisphosphate to 1,2-diacylglycerol and inositol 1,4,5-trisphosphate. Inositol 1,4,5-trisphosphate has been directly implicated in the release of $\mathrm{Ca}^{2+}$ from the endoplasmic reticulum into the cytosol while 1,2-diacylglycerol has also been shown to act as a signal molecule by enhancing the $\mathrm{Ca}^{2+}$ sensitivity of protein kinase $\mathrm{C}(1-4)$. In several cell types the stimulation of phosphatidylinositol hydrolysis and $\mathrm{Ca}^{2+}$ mobilization leads to the release of arachidonic acid and its metabolites, and has been found to increase guanosine $3^{\prime}, 5^{\prime}$-cyclic

Address correspondence to Dr. Brotherton, Department of Medicine, University of Iowa, Iowa City, IA 52242. 1986.

Received for publication 16 October 1985 and in revised form 21 May

J. Clin. Invest.

(c) The American Society for Clinical Investigation, Inc. 0021-9738/86/11/1253/08 $\$ 1.00$

Volume 78, November 1986, 1253-1260 monophosphate (cyclic GMP) ${ }^{1}$ accumulation $(3,4)$. Thus, $\mathrm{Ca}^{2+}$ mobilization, arachidonic acid release, and cyclic GMP formation appear to be integrated in a single receptor cascade.

Although a wide variety of agents stimulate prostacyclin $\left(\mathrm{PGI}_{2}\right)$ biosynthesis in vascular endothelium (reviewed in reference 5), little is known regarding the specific mechanisms involved in the induction and regulation of $\mathrm{PGI}_{2}$ production. $\mathrm{Re}$ sults of previous studies (6) demonstrate that cyclic AMP does not mediate the effects of stimuli of $\mathrm{PGI}_{2}$ biosynthesis, nor does it appear to be involved in the short-term regulation of $\mathrm{PGI}_{2}$ production in primary cultures of human umbilical vein endothelium. Conversely, $\mathrm{Ca}^{2+}$ does appear to have a predominant role as an intracellular mediator in the secretory processes of endothelial cells, as $\mathrm{Ca}^{2+}$ ionophores such as A23187 can stimulate $\mathrm{PGI}_{2}$ production (5-8). It has not yet been demonstrated that extracellular signals such as thrombin, bradykinin, and histamine stimulate $\mathrm{Ca}^{2+}$ mobilization in endothelial cells via phosphatidylinositol hydrolysis. In light of the close association between the stimulation of phosphatidylinositol hydrolysis and increased cyclic GMP accumulation that has been observed in many cell types $(3,4)$, the present study was carried out to determine whether a similar relationship exists in cultured endothelium with respect to the induction of $\mathrm{PGI}_{2}$ biosynthesis.

The studies reported in this paper demonstrate that the induction of $\mathrm{PGI}_{2}$ biosynthesis in primary cultures of human umbilical vein endothelium is closely associated with a rapid increase in the intracellular concentration of cyclic GMP, and, that this increase in cyclic GMP results from the activation of guanylate cyclase by factors generated before the release and metabolism of arachidonic acid.

\section{Methods}

Materials. Unless noted otherwise, supplies and reagents were purchased from Sigma Chemical Co., St. Louis, MO. Other materials included: Type I collagenase from Cooper Biochemical Inc., Malvern, PA; powdered Medium 199 (with Earle's salts, with L-glutamine, and without $\mathrm{NaHCO}_{3}$ ), Eagle's basal medium vitamin solution $(\times 100)$, Eagle's basal medium amino acid solution $(\times 100)$, L-glutamine, and neomycin sulfate from Gibco, Grand Island, NY; fetal calf serum (FCS) from Armour Pharmaceutical Co., Tarrytown, NY; fatty acid poor bovine albumin (fraction V) from Miles Laboratories, Elkhart, IN; normal rabbit serum from Cappel Laboratories, Cochranville, PA; fibronectin from Collaborative Research Inc., Boston, MA; IgG sorb from The Enzyme Center, Malden, MA; multiwell tissue culture plates from Flow Laboratories, McClean, VA; [ $\left.{ }^{125} \mathrm{I}\right] 2^{\prime}-O$-succinyl (iodotyrosine methyl ester) cyclic GMP (2,000-3,000 Ci/mmol), [8- $\left.{ }^{3} \mathrm{H}\right]$ cyclic GMP (5-15 Ci/mmol), and cyclic

1. Abbreviations used in this paper: cyclic GMP, guanosine 3',5'-cyclic monophosphate; ETYA, 5,8,11,14-eicosatetraynoic acid; FCS, fetal calf serum; MIX, 1-methyl-3-isobutylxanthine; MM-199, modified Medium199; $P F_{1}$ and $P G F_{2}$, prostaglandins $F_{1}$ and $F_{2} ; P_{2}$, prostacyclin; TBS, Tris-buffered saline. 
GMP antiserum complex from New England Nuclear, Boston, MA; 6keto-[5,8,9,11,12,14,15(n)- $\left.{ }^{3} \mathrm{H}\right]$ prostaglandin $\mathrm{F}_{1 \alpha}\left(\mathrm{PGF}_{1 \alpha}\right)(150 \mathrm{Ci} / \mathrm{mmol})$ from Amersham Corp., Arlington Heights, IL; 6-keto-PGF I $_{1 \alpha}$ and other prostaglandins from the Upjohn Co., Kalamazoo, MI; bradykinin from Vega Biochemicals, Tucson, AZ; A23187 from Calbiochem-Behring Corp., San Diego, CA: arachidonic acid from Nu Chek Prep, Inc., Elysian, MN; atriopeptin III from Penninsula Laboratories Inc., Belmont, CA; and, Ready-Solv CP liquid scintillation cocktail from Beckman Instruments Inc., Fullerton, CA. Purified thrombin $(\sim 2,600 \mathrm{NIH} \mathrm{U} / \mathrm{mg}$ protein) (9) was provided by Dr. Ruth Ann Henriksen, Dept. of Pathology, University of Iowa.

Endothelial cell cultures. Primary cultures of human endothelial cells from umbilical cords were prepared by a modification of the method originally described by Jaffe et al. (10). Umbilical cords $<24$-h-old were cleaned and the veins rinsed free of blood with phosphate-buffered saline (PBS), pH 7.4 (0.14 M NaCl, $0.003 \mathrm{M} \mathrm{KCl}, 0.0012 \mathrm{M} \mathrm{KH}_{2} \mathrm{PO}_{4}, 0.008$ $\mathrm{M} \mathrm{Na}_{2} \mathrm{HPO}_{4}$, and $0.01 \mathrm{~g}$ /liter phenol red). Cords were clamped and the vein was filled with PBS containing 0.1\% Type I collagenase. Enzymatic digestion was continued for $6 \mathrm{~min}$ at room temperature. The vein was drained and then rinsed with a total of $\sim 50 \mathrm{ml}$ of modified Medium199 (MM-199) (8) containing 10\% heat-inactivated FCS. The cells were sedimented at $300 \mathrm{~g}$ for $10 \mathrm{~min}$ and then resuspended with $\sim 5-10 \mathrm{ml}$ of MM-199 with 20\% FCS. The cell count of the suspension was adjusted to $4.5 \times 10^{5}$ cells $/ \mathrm{ml} ; 1 \mathrm{ml}$ of this suspension was added to each well of a 12-well tissue culture plate. Cells were incubated at $37^{\circ} \mathrm{C}$ under $5 \%$ $\mathrm{CO}_{2} .4 \mathrm{~h}$ after seeding, the medium was removed and the monolayers were rinsed with $1 \mathrm{ml}$ of MM-199; $1 \mathrm{ml}$ of MM-199 containing 20\% FCS was then layered onto each monolayer. Confluent endothelial cell monolayers were used 3-4 d after seeding. On average, the concentration of protein in acid-precipitated monolayers of endothelial cells from 60 separate pools was $129 \pm 8 \mu \mathrm{g}$ protein per $4.5 \times 10^{5}$ cells (mean \pm SEM).

Incubation procedure. Immediately before each experiment, culture medium was aspirated from the monolayers, which were then rinsed twice with $1 \mathrm{ml}$ of Hanks'-Hepes buffer $\left(0.0013 \mathrm{M} \mathrm{CaCl}_{2}, 0.0054 \mathrm{M}\right.$ $\mathrm{KCl}, 0.0003 \mathrm{M} \mathrm{KH}_{2} \mathrm{PO}_{4}, 0.0005 \mathrm{M} \mathrm{MgCl}_{2}, 0.1369 \mathrm{M} \mathrm{NaCl}, 0.0003 \mathrm{M}$ $\mathrm{Na}_{2} \mathrm{HPO}_{4}, 0.0056 \mathrm{M}$ glucose, $0.015 \mathrm{M}$ Hepes, and $0.01 \mathrm{~g} /$ liter phenol red; $\mathrm{pH}$ 7.4). Monolayers were usually incubated for $5 \mathrm{~min}$ at $37^{\circ} \mathrm{C}$ with $500 \mu$ l Hanks'-Hepes buffer with or without the test stimulus. At the end of the incubation period, the buffer was removed from the monolayers and frozen at $-20^{\circ} \mathrm{C}$ until it was assayed for 6-keto-PGF $1 \alpha$.

Radioimmunoassay of 6-keto-PGF $F_{l \alpha}$. The radioimmunoassay of 6keto- PGF $_{1 \alpha}$ is a modification of a previously described method (11). Assay tubes (1.5-ml micro test tubes) were prepared by adding $100 \mu \mathrm{l}$ of sample or standard (in Hanks'-Hepes buffer), $50 \mu \mathrm{l}$ of antiserum (to give a total dilution of 1:2,500) in Tris-buffered saline (TBS) $(0.139 \mathrm{M} \mathrm{NaCl}$ and $15 \mathrm{mM}$ Tris, pH 7.4), and $50 \mu \mathrm{l}$ of a solution containing $\sim 10,000$ cpm of $\left[{ }^{3} \mathrm{H}\right] 6-k e t o-P G F_{1 \alpha}$ in TBS with $0.1 \%$ bovine gamma globulin. Six concentrations of 6-keto- $\mathrm{PGF}_{1 \alpha}$ are included in the standard curve, which ranges from 0.25 to $10 \mathrm{pmol} / 100 \mu \mathrm{l}$. After incubation at $37^{\circ} \mathrm{C}$ for $1 \mathrm{~h}$, bound radioactivity was separated from free by the addition of 25 $\mu$ l of a $50 \%$ suspension of IgG sorb in TBS. The tubes were vortexed and centrifuged at $12,000 \mathrm{~g}$ for $4 \mathrm{~min}$. Aliquots $(150 \mu \mathrm{l})$ of the supernate were added to $4 \mathrm{ml}$ of Ready-Solv CP liquid scintillation cocktail (Beckman Instruments Inc.). The samples were counted using an LS 2800 liquid scintillation counter (Beckman Instruments Inc.) equipped with radioimmunoassay data reduction software; data were calculated by weighted linear regression analysis of a logit-log curve. All samples were assayed at a minimum of two dilutions. Assay detection limits are $\mathbf{2 . 5}$ nM 6-keto-PGF $F_{1 \alpha}$, and $50 \%$ displacement of $\left[{ }^{3} \mathrm{H}\right] 6-$ keto-PGF ${ }_{1 \alpha}$ is obtained with 2.0-2.2 pmol of 6-keto-PGF $1 \alpha / 100 \mu$ l. This assay has $4 \%$ crossreactivity with $\mathrm{PGF}_{1 \alpha}, 2 \%$ with $\mathrm{PGF}_{2 \alpha}, 1.6 \%$ with prostaglandin $\mathrm{E}_{2}$, and $<1 \%$ with prostaglandins $\mathrm{E}_{1}, \mathrm{E}$, or $\mathrm{E}_{2}$.

Extraction and isolation of cyclic GMP. To extract cyclic GMP, 1 $\mathrm{ml}$ of ice-cold $10 \%$ trichloroacetic acid (vol/vol) was added to each monolayer immediately after removal of the incubation buffer. The tissue culture plates were placed on ice for $10 \mathrm{~min}$, and $25 \mu \mathrm{l}$ of a solution containing $\sim 4,000 \mathrm{cpm}$ of $\left[{ }^{3} \mathrm{H}\right]$ cyclic GMP was added to each monolayer. To isolate cyclic GMP, the acid extract from each monolayer was added to a column (Pasteur pipette) containing $1 \mathrm{ml}$ of packed Dowex AG $50 \mathrm{~W}-4 \times$ resin that had first been washed with $0.05 \mathrm{~N} \mathrm{HCl}$, cyclic GMP was then eluted with $3 \mathrm{ml}$ of $0.05 \mathrm{~N} \mathrm{HCl}$. The eluates from the Dowex column were then applied to another set of columns containing $0.8 \mathrm{~g}$ of neutral alumina that had first been washed with $5 \%$ (vol/vol) trichloroacetic acid. The columns were washed with $5 \mathrm{ml}$ of $\mathrm{H}_{2} \mathrm{O}$ followed by $1 \mathrm{ml}$ of $0.2 \mathrm{M}$ sodium acetate buffer, $\mathrm{pH}$ 6.2; cyclic GMP was then eluted with an additional $1 \mathrm{ml}$ of this buffer. Recovery of $\left[{ }^{3} \mathrm{H}\right]$ cyclic GMP ranged from 65 to $70 \%$.

Radioimmunoassay of cyclic GMP. Cyclic GMP was assayed according to the protocol used for the radioimmunoassay of cyclic AMP described by Brotherton et al. (6). $100 \mu \mathrm{l}$ of sample or standard solution (in $0.2 \mathrm{M}$ sodium acetate buffer, $\mathrm{pH}$ 6.2) was transferred to a micro test tube and $5 \mu$ l of freshly prepared acetic anhydride/triethylamine (1:2) was added; this was followed by immediate vortex mixing. Assay tubes (10 $\times 75$-mm disposable glass culture tubes) were prepared by adding: $40 \mu \mathrm{l}$ of acetylated sample or standard; $40 \mu \mathrm{l}$ of a solution of 8,000 $12,000 \mathrm{cpm}$ of $\left.{ }^{125} \mathrm{I}\right] 2^{\prime}-O$-succinyl(iodotyrosine methyl ester) cyclic GMP and $1 \%$ normal rabbit serum in $0.2 \mathrm{M}$ sodium acetate buffer, $\mathrm{pH}$ 6.2; and $40 \mu \mathrm{l}$ of cyclic GMP antiserum complex diluted according to the manufacturer's instructions. Smaller sample volumes may be assayed, provided that acetylated $0.2 \mathrm{M}$ sodium acetate buffer is added, to give a total sample volume of $40 \mu$ l. Alternatively, samples may be diluted with buffer before the acetylation step. Eight concentrations of cyclic GMP are included in the standard curve, which ranges from 2.5 to 500 fmol/40 $\mu \mathrm{l}$. After incubation at $4^{\circ} \mathrm{C}$ for $16-24 \mathrm{~h}, 1 \mathrm{ml}$ of ice-cold $95 \%$ ethanol was added to each tube to precipitate bound radioactivity. The tubes were then centrifuged at $2,000 \mathrm{~g}$ for $15 \mathrm{~min}$ at $4^{\circ} \mathrm{C}$, the supernates aspirated, and the dried precipitates counted on a DP 5000 gamma counter (Beckman Instruments Inc.). Under these conditions, $50 \%$ displacement of $\left[{ }^{125} \mathrm{I}\right] 2^{\prime}-O$-succinyl (iodotyrosine methyl ester) cyclic GMP from cyclic GMP is obtained with 12-15 fmol of cyclic GMP/40 $\mu \mathrm{l}$, and $\sim 30 \%$ of average net total counts are bound in the absence of cyclic GMP. All samples were assayed at a minimum of two dilutions and the concentration of cyclic GMP was corrected for recovery.

Statistical analysis. Statistical significance was determined by the Students $t$ test; a $P$ value of $<0.005$ was chosen to denote statistical significance between groups. Unless indicated otherwise, the data are reported as means \pm SEM of triplicate determinations from the same experiment. In all cases, similar findings were obtained in a minimum of two other experiments.

\section{Results}

A wide variety of agents that stimulate $\mathbf{P G I}_{2}$ biosynthesis in primary monolayer cultures of human umbilical vein endothelium have been found to stimulate cyclic GMP accumulation in these cells. As shown in Table I, thrombin, the calcium ionophore A23187, bradykinin, and histamine increased the intracellular concentration of cyclic GMP by an average of about twofold during a 5-min incubation period. By contrast, arachidonic acid had no effect on cyclic GMP accumulation. The concentration of each agent tested was selected to stimulate maximal or near-maximal release of $\mathrm{PGI}_{2}$ (see legend of Table I). To determine whether the observed increases in cyclic GMP resulted from increased synthesis (activation of guanylate cyclase) or decreased degradation (inhibition of cyclic GMP phosphodiesterase), studies were carried out in the presence of 1-methyl-3-isobutylxanthine (MIX), a cyclic nucleotide phosphodiesterase inhibitor. Incubation of endothelial monolayers for a total of 10 min with $1 \mathrm{mM}$ MIX increased the basal level of cyclic GMP by an average of 7.4 \pm 1.0 -fold (Table I). Nearly maximal increases $(\sim 80 \%)$ in cyclic GMP were obtained with 1 mM MIX; maximal increases were observed with $4 \mathrm{mM}$ MIX and half-maximal with $0.5 \mathrm{mM}$ MIX. As shown in Table I, much larger increases in the intracellular concentration of cyclic GMP were obtained in 
Table I. Effect of Stimuli of PGI ${ }_{2}$ Biosynthesis on Cyclic GMP Accumulation

\begin{tabular}{|c|c|c|c|c|c|c|c|}
\hline \multirow[b]{3}{*}{ Addition } & \multicolumn{3}{|c|}{$\begin{array}{l}\text { Concentration of cyclic GMP in monolayers } \\
\text { preincubated without MIX }\end{array}$} & \multicolumn{3}{|c|}{$\begin{array}{l}\text { Concentration of cyclic GMP in monolayers } \\
\text { preincubated with } 1 \mathrm{mM} \text { MIX }\end{array}$} & \multirow{3}{*}{$\begin{array}{l}\text { No. of } \\
\text { exps. }\end{array}$} \\
\hline & Control & + Stimulus & \multirow{2}{*}{$\begin{array}{l}\text { Fold } \\
\text { increase }\end{array}$} & Control & + Stimulus & \multirow{2}{*}{$\begin{array}{l}\text { Fold } \\
\text { increase }\end{array}$} & \\
\hline & \multicolumn{2}{|c|}{ pmol cyclic GMP/4.5 $\times 10^{5}$ cells } & & \multicolumn{2}{|c|}{ pmol cyclic GMP/4.5 × $10^{5}$ cells } & & \\
\hline None (control) & $0.85 \pm 0.05$ & - & - & $6.53 \pm 1.05^{*}$ & - & 一 & 23 \\
\hline Thrombin $(0.5 \mathrm{U} / \mathrm{ml})$ & $0.81 \pm 0.05$ & $1.44 \pm 0.17$ & $1.8 \pm 0.2$ & $6.33 \pm 1.18$ & $63.13 \pm 7.46$ & $12.3 \pm 1.2$ & 10 \\
\hline $\mathrm{A} 23187(4 \mu \mathrm{M})$ & $0.84 \pm 0.06$ & $1.70 \pm 0.13$ & $2.1 \pm 0.1$ & $6.75 \pm 1.03$ & $57.76 \pm 4.56$ & $10.5 \pm 1.2$ & 20 \\
\hline Bradykinin $(10 \mu \mathrm{M})$ & $0.74 \pm 0.02$ & $1.28 \pm 0.13$ & $1.7 \pm 0.2$ & $6.85 \pm 1.45$ & $60.75 \pm 14.21$ & $10.8 \pm 2.6$ & 4 \\
\hline Histamine $(10 \mu \mathrm{M})$ & $0.75 \pm 0.03$ & $1.38 \pm 0.13$ & $1.8 \pm 0.1$ & $7.20 \pm 1.58$ & $62.26 \pm 11.55$ & $10.5 \pm 2.4$ & 4 \\
\hline Arachidonic acid ( $4 \mu \mathrm{M})$ & $0.88 \pm 0.05$ & $0.88 \pm 0.03 \ddagger$ & $1.0 \pm 0.1$ & $6.69 \pm 2.00$ & $6.35 \pm 1.56 \ddagger$ & $1.0 \pm 0.1$ & 5 \\
\hline
\end{tabular}

Endothelial monolayers were preincubated at $37^{\circ} \mathrm{C}$ for 5 min with $475 \mu \mathrm{l}$ of Hanks'-Hepes buffer alone (controls) or Hanks'-Hepes buffer containing $1 \mathrm{mM}$ MIX. After the preincubation period, $25 \mu \mathrm{l}$ of Hanks'-Hepes buffer containing the test agent (at an initial concentration 20 -fold higher than the final concentration) was added to the preincubation buffer and incubations were continued for 5 min. All values are expressed as means \pm SEM. The production of 6-keto-PGF F $_{1 \alpha}$ in monolayers preincubated with buffer followed by a 5-min incubation with the indicated test agent is as follows: $21 \pm 3 \mathrm{nM}$ (control); $337 \pm 28 \mathrm{nM}$ (thrombin); $510 \pm 32 \mathrm{nM}$ (A23187); $212 \pm 28 \mathrm{nM}$ (bradykinin); $473 \pm 39 \mathrm{nM}$ (histamine); and $490 \pm 42 \mathrm{nM}$ (arachidonic acid), at the concentrations and number of experiments indicated for each agent. * Preincubation of endothelial monolayers with $1 \mathrm{mM}$ MIX increased the intracellular concentration of cyclic GMP by $7.4 \pm 1.0$-fold. $¥$ No significant difference compared with control value.

response to stimuli of $\mathrm{PGI}_{2}$ biosynthesis when endothelial monolayers were preincubated with $1 \mathrm{mM}$ MIX. With the exception of arachidonic acid, which had no effect, each of the other agents increased cyclic GMP levels by an average of about tenfold in the presence of MIX (Table I). Thus, the effects of these treatments are additive. This finding suggests that stimuli of $\mathrm{PGI}_{2}$ biosynthesis that increase the intracellular concentration of cyclic GMP, act by a mechanism involving activation of guanylate cyclase and not inhibition of cyclic GMP phosphodiesterase.

The lack of an effect of arachidonic acid on cyclic GMP accumulation suggests that neither arachidonic acid itself nor its metabolites activate guanylate cyclase in primary human umbilical vein endothelium. Additional evidence in support of this hypothesis is provided by studies of the effects of inhibitors of arachidonic acid release and of its subsequent metabolism on both $\mathrm{PGI}_{2}$ production and cyclic GMP accumulation. These agents included: quinacrine, an inhibitor of phospholipase $A_{2}$; aspirin and ibuprofen, cyclooxygenase inhibitors; and 5,8,11,14eicosatetraynoic acid (ETYA), a lipoxygenase inhibitor. As shown in Table II, pretreatment of endothelial monolayers with $100 \mu \mathrm{M}$ quinacrine decreased $\mathrm{PGI}_{2}$ production in response to thrombin and $A 23187$ by $\sim 69$ and $52 \%$, respectively, but had no effect on the stimulation of cyclic GMP accumulation by either of these agents in the absence or presence of MIX. Note that quinacrine had no effect on $\mathrm{PGI}_{2}$ production in response to arachidonic acid. In monolayers that had been pretreated with $100 \mu \mathrm{M}$ aspirin or $500 \mu \mathrm{M}$ ibuprofen, $\mathrm{PGI}_{2}$ production in response to all stimuli tested was abolished; however, the stimulation of cyclic GMP accumulation was unaffected. Similar

Table II. Effect of Quinacrine on $\mathrm{PGI}_{2}$ Biosynthesis and Cyclic GMP Accumulation

\begin{tabular}{|c|c|c|c|c|}
\hline \multirow[b]{2}{*}{ Additions } & & \multirow[b]{2}{*}{ 6-Keto-PGF ${ }_{1 e^{*}}$} & \multicolumn{2}{|c|}{ Cyclic GMP (pmol/4.5 × $10^{5}$ cells) } \\
\hline & & & Control & MIX (1 mM) \\
\hline & & $n M$ & & \\
\hline \multirow[t]{4}{*}{ Control } & None & $23 \pm 3$ & $0.96 \pm 0.04$ & $4.27 \pm 0.32$ \\
\hline & Thrombin $(0.5 \mathrm{U} / \mathrm{ml})$ & $210 \pm 13$ & $1.84 \pm 0.07$ & $45.08 \pm 3.07$ \\
\hline & $\mathrm{A} 23187(4 \mu \mathrm{M})$ & $372 \pm 28$ & $2.27 \pm 0.12$ & $49.97 \pm 2.56$ \\
\hline & Arachidonic acid $(4 \mu \mathrm{M})$ & $400 \pm 32$ & $0.90 \pm 0.05$ & $4.02 \pm 0.29$ \\
\hline \multirow[t]{4}{*}{ Quinacrine $(100 \mu \mathrm{M})$} & None & $9 \pm 2$ & $1.04 \pm 0.06$ & $4.33 \pm 0.21$ \\
\hline & Thrombin $(0.5 \mathrm{U} / \mathrm{ml})$ & $69 \pm 7$ & $1.79 \pm 0.05$ & $47.19 \pm 2.95$ \\
\hline & A23187 (4 $\mu \mathrm{M})$ & $159 \pm 12$ & $2.34 \pm 0.18$ & $48.51 \pm 4.09$ \\
\hline & Arachidonic acid $(4 \mu \mathrm{M})$ & $422 \pm 25$ & $0.99 \pm 0.03$ & $4.31 \pm 0.32$ \\
\hline
\end{tabular}

Endothelial monolayers were preincubated at $37^{\circ} \mathrm{C}$ for 15 min with $475 \mu$ l of Hanks'-Hepes buffer alone or Hanks'-Hepes buffer containing 100 $\mu \mathrm{M}$ quinacrine with and without $1 \mathrm{mM}$ MIX. After the preincubation period, $25 \mu \mathrm{l}$ of Hanks'-Hepes buffer alone or Hanks'-Hepes buffer containing the test agent (at an initial concentration 20-fold higher than the final concentration) was added to the preincubation media and the incubations were continued for $5 \mathrm{~min}$. Values are expressed as means of triplicate determinations; similar findings were obtained in four other experiments. * 6-Keto-PGF $1 \alpha$ production in monolayers preincubated $15 \mathrm{~min}$ with Hanks'-Hepes buffer \pm quinacrine followed by a 5-min incubation with the indicated stimulus. 
findings were obtained with ETYA at concentrations ranging from 1 to $20 \mu \mathrm{M}$. Taken together, these results suggest that the increase in cyclic GMP observed in response to stimuli of $\mathrm{PGI}_{2}$ production results from the activation of guanylate cyclase by factors generated before the release and metabolism of arachidonic acid.

To examine the role of extracellular $\mathrm{Ca}^{2+}$ in the induction of $\mathrm{PGI}_{2}$ biosynthesis and cyclic GMP accumulation, experiments were carried out using $\mathrm{Ca}^{2+}$-free buffer (Hanks'-Hepes buffer with $1.3 \mathrm{mM} \mathrm{CaCl}{ }_{2}$ omitted). Incubations were as described in Methods, with the exception that monolayers were rinsed three times with $1 \mathrm{ml}$ of $\mathrm{Ca}^{2+}$-free Hanks'-Hepes buffer before the addition of the test stimulus. Endothelial monolayers were also grown on fibronectin-coated plates, as preliminary studies showed that omission of $\mathrm{Ca}^{2+}$ from the buffer resulted in partial detachment of the monolayers from the surface of the tissueculture plate. As shown in Table III, omission of $\mathrm{Ca}^{2+}$ had no significant effect on $\mathrm{PGI}_{2}$ production in response to stimulation by thrombin. By contrast, the effect of A23187 was decreased by $\sim 40 \%$ as compared with values obtained in the presence of $\mathrm{Ca}^{2+}$. However, neither thrombin nor $\mathrm{A} 23187$ had a significant effect on cyclic GMP accumulation in the absence of both $\mathrm{Ca}^{2+}$ and MIX. In monolayers that had been preincubated with 1 mM MIX, thrombin and A23187 increased cyclic GMP levels by an average of only 2.0- and 3.4-fold, respectively, in $\mathrm{Ca}^{2+}$ free buffer, whereas increases of 7.6- and 6.6-fold, respectively, were observed in the presence of extracellular $\mathrm{Ca}^{2+}$ (Table III). Thus, the stimulatory effect of thrombin on cyclic GMP accumulation appears to be more dependent on the availability of extracellular $\mathrm{Ca}^{2+}$ than the effect of A23187. Significant differences therefore exist with respect to the requirements of the endothelium for extracellular $\mathrm{Ca}^{2+}$ for the stimulation of $\mathbf{P G I}_{2}$ biosynthesis as compared with cyclic GMP accumulation in response to thrombin or A23187 (Table III).

The relationship between cyclic GMP accumulation in re-

Table III. Effect of Extracellular $\mathrm{Ca}^{2+}$ on $\mathrm{PGI}_{2}$ Biosynthesis and Cyclic GMP Accumulation

\begin{tabular}{|c|c|c|c|c|}
\hline \multirow[b]{2}{*}{ Additions } & & \multirow[b]{2}{*}{ 6-Keto-PGF ${ }_{12}^{*}$} & \multicolumn{2}{|c|}{$\begin{array}{l}\text { Cyclic GMP } \\
\left(\mathrm{pmol} / 4.5 \times 10^{5} \text { cells }\right)\end{array}$} \\
\hline & & & Control & MIX (1 mM) \\
\hline & & $n M$ & & \\
\hline \multirow[t]{4}{*}{$+\mathrm{Ca}^{2+}$} & None (control) & $43 \pm 3$ & $1.27 \pm 0.05$ & $3.89 \pm 0.26$ \\
\hline & Thrombin & & & \\
\hline & $(0.5 \mathrm{U} / \mathrm{ml})$ & $266 \pm 11$ & $1.93 \pm 0.19$ & $29.41 \pm 1.03$ \\
\hline & A23187 (4 $\mu \mathrm{M})$ & $359 \pm 35$ & $2.14 \pm 0.18$ & $25.70 \pm 1.42$ \\
\hline \multirow[t]{4}{*}{$-\mathrm{Ca}^{2+} \ddagger$} & None (control) & $57 \pm 5$ & $1.21 \pm 0.08$ & $2.84 \pm 0.21$ \\
\hline & Thrombin & & & \\
\hline & $(0.5 \mathrm{U} / \mathrm{ml})$ & $276 \pm 13$ & $1.31 \pm 0.05$ & $5.76 \pm 0.28$ \\
\hline & A23187 (4 $\mu \mathrm{M})$ & $147 \pm 13$ & $1.29 \pm 0.04$ & $9.62 \pm 0.80$ \\
\hline
\end{tabular}

Endothelial monolayers were preincubated at $37^{\circ} \mathrm{C}$ for $5 \mathrm{~min}$ with $475 \mu \mathrm{l}$ of Hanks'-Hepes buffer alone $\left( \pm \mathrm{CaCl}_{2}\right)$ (controls) or Hanks'-Hepes buffer containing $1 \mathrm{mM} \mathrm{MIX}\left( \pm \mathrm{CaCl}_{2}\right)$. At the end of the preincubation period, $25 \mu \mathrm{l}$ of Hanks'-Hepes buffer containing the test agent (at an initial concentration 20fold higher than the final concentration) was added to the preincubation buffer and incubations were continued for $5 \mathrm{~min}$. All values are expressed as means \pm SEM of triplicate determinations from the same experiment; similar findings were obtained in two other experiments.

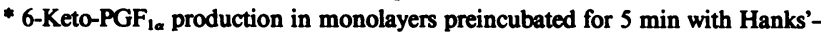
Hepes buffer $\left( \pm \mathrm{CaCl}_{2}\right)$ followed by a 5-min incubation with the indicated test agent.

‡ Hanks'-Hepes buffer with $1.3 \mathrm{mM} \mathrm{CaCl}_{2}$ omitted. sponse to thrombin and A23187 and incubation time is shown in Fig. 1. In monolayers preincubated with buffer alone (Fig. 1 $A$ ), thrombin and A23187 stimulate significant increases in cyclic GMP by $30 \mathrm{~s}$; maximum increases were reached by $2 \mathrm{~min}$. In monolayers exposed to thrombin, cyclic GMP levels slowly returned to baseline by $20 \mathrm{~min}$. By contrast, cyclic GMP levels in monolayers exposed to A23187 remained half-maximally elevated for at least $40 \mathrm{~min}$ (Fig. $1 \mathrm{~A}$ ). In monolayers preincubated with $1 \mathrm{mM}$ MIX (Fig. $1 \mathrm{~B}$ ), maximal increases in cyclic GMP were obtained by $10 \mathrm{~min}$ in response to thrombin or A23187. After $10 \mathrm{~min}$, thrombin-induced increases in cyclic GMP slowly declined; by $40 \mathrm{~min}$, cyclic GMP levels approached baseline and were comparable with those observed after 5-min incubation. Findings similar to those seen with thrombin were obtained with bradykinin and histamine. In contrast to the effect of physiologic stimuli, cyclic GMP levels remained maximally elevated for as long as $\mathbf{4 0} \mathrm{min}$ in the presence of both A23187 and MIX (Fig. $1 B$ ). This observation suggests that exposure of endothelial monolayers to A23187 results in a sustained activation of guanylate cyclase, whereas exposure to thrombin, bradykinin, and histamine results in a transient activation of this enzyme.

The concentration-response relationships of the effect of A23187 on $\mathrm{PGI}_{2}$ biosynthesis and cyclic GMP accumulation are shown in Fig. 2. During a 5-min incubation period, maximal increases in $\mathrm{PGI}_{2}$ production and cyclic GMP accumulation between 4 and $10 \mu \mathrm{M}$ of A23187. Significant increases in cyclic GMP were observed with $0.04 \mu \mathrm{M}$ A23187, whereas $0.1 \mu \mathrm{M}$ A23187 was required to induce significant increases in $\mathbf{P G I}_{2}$ biosynthesis. Half-maximal increases in cyclic GMP and $\mathbf{P G I}_{2}$ production were obtained with 0.1 and $0.4 \mu \mathrm{M}$ of $\mathrm{A} 23187$, respectively (Fig. $2 A$ ). In the presence of MIX, exposure of endothelial monolayers to A23187 produced much larger increases in cyclic GMP (Fig. $2 \mathrm{~B}$ ) despite the inhibition of $\mathrm{PGI}_{2}$ biosynthesis observed with this agent $(6,8)$. The dose-response relationships of the effect of A23187 on both cyclic GMP accumulation and $\mathrm{PGI}_{2}$ production parallel those observed in monolayers preincubated with buffer alone. Qualitatively, similar

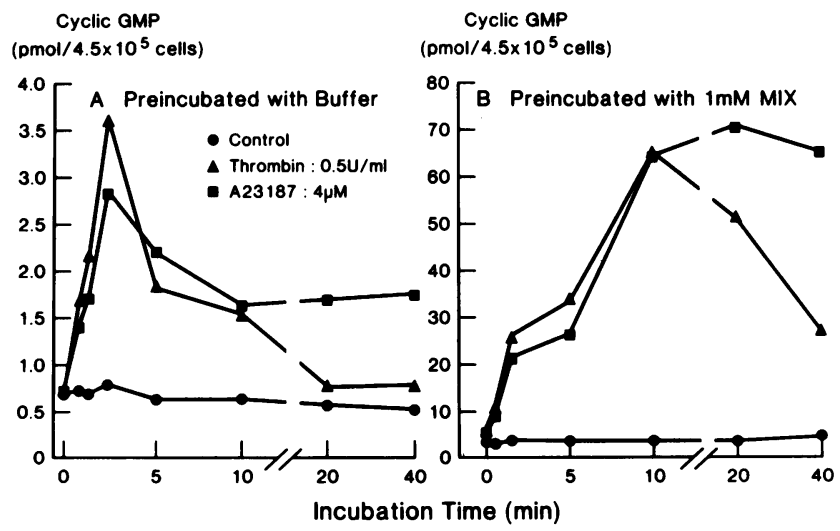

Figure 1. Effect of incubation time on cyclic GMP accumulation in the $(A)$ absence and $(B)$ presence of MIX. Endothelial monolayers were preincubated at $37^{\circ} \mathrm{C}$ for $5 \mathrm{~min}$ with $475 \mu \mathrm{l}$ of $(A)$ Hanks'-Hepes buffer alone or $(B)$ Hanks'-Hepes buffer containing 1 mM MIX. After the preincubation period, $25 \mu \mathrm{l}$ of Hanks'-Hepes buffer alone or containing the test agent (at an initial concentration 20-fold higher than the final concentration) was added to the preincubation buffer and incubations were continued as indicated. Values are expressed as means of duplicate determinations; similar findings were obtained in two other experiments. 


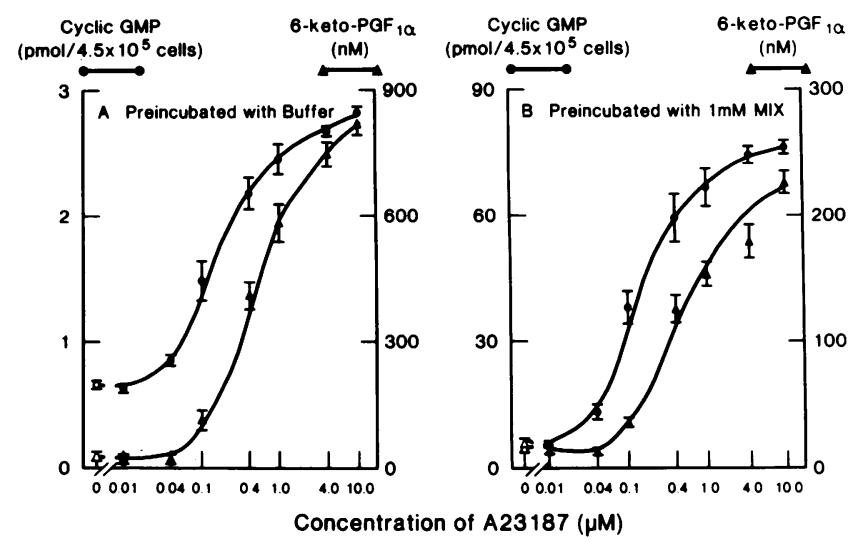

Figure 2. Concentration-response relationships of the effect of A23187 on cyclic GMP accumulation and $\mathrm{PGI}_{2}$ production in the $(A)$ absence and $(B)$ presence of $1 \mathrm{mM}$ MIX. Endothelial monolayers were preincubated at $37^{\circ} \mathrm{C}$ for 5 min with $475 \mu$ of $(A)$ Hanks'-Hepes buffer alone or $(B)$ Hanks'-Hepes buffer containing $1 \mathrm{mM}$ MIX. After the preincubation period, $25 \mu \mathrm{l}$ of Hanks'-Hepes buffer alone or containing the A23187 (at an initial concentration 20-fold higher than the final concentration indicated) was added to the preincubation buffer and incubations were continued for $5 \mathrm{~min}$. Values are expressed as means \pm SEM or triplicate determinations; similar findings were obtained in two other experiments.

findings were obtained with thrombin, bradykinin, or histamine (data not shown).

To determine whether cyclic GMP mediates the induction or is involved in the regulation of $\mathrm{PGI}_{2}$ biosynthesis in the endothelium, the effects of several agents known to increase cyclic GMP accumulation in other cell types were tested. These included norepinephrine, acetylcholine, atriopeptin III, tert-butylhydroperoxide, and sodium nitroprusside. Although neither norepinephrine or acetylcholine, at concentrations ranging from 0.1 to $100 \mu \mathrm{M}$, had detectable effects on $\mathrm{PGI}_{2}$ biosynthesis or cyclic GMP accumulation, atriopeptin III, tert-butylhydroperoxide, and sodium nitroprusside stimulated significant increases in the intracellular concentration of cyclic GMP without an associated increase in $\mathrm{PGI}_{2}$ biosynthesis. The dose-response relationship of the effect of atriopeptin III on cyclic GMP accumulation in the absence and presence of MIX is shown in Fig. 3. Even though the stimulatory effect of atriopeptin III on cyclic GMP accumulation is comparable with that observed in response to thrombin, bradykinin, histamine, or A23187 (see Table I), no increase in $\mathrm{PGI}_{2}$ production over basal levels was observed at any concentration of this peptide tested. Table IV shows that cyclic GMP levels were increased by about the same extent, either in the absence or presence of MIX, by tert-butylhydroperoxide, sodium nitroprusside, or A23187. Like atriopeptin III, sodium nitroprusside had no effect on $\mathrm{PGI}_{2}$ biosynthesis; conversely, tert-butylhydroperoxide had a very small but statistically significant stimulatory effect. The data shown in Fig. 4 indicate that this effect of tert-butylhydroperoxide on $\mathrm{PGI}_{2}$ production is unrelated to its effect on cyclic GMP accumulation. First, significant increases in cyclic GMP were observed only in response to 40 or $100 \mu \mathrm{M}$ tert-butylhydroperoxide, whereas $\mathrm{PGI}_{2}$ production increased progressively with up to $1,000 \mu \mathrm{M}$ of this agent. Second, the concentration of tert-butylhydroperoxide that had the greatest effect on $\mathrm{PGI}_{2}$ production (i.e., $400 \mu \mathrm{M}$ ) had no detectable effect on cyclic GMP accumulation. These findings support the conclusion that an increase in the intracellular con-

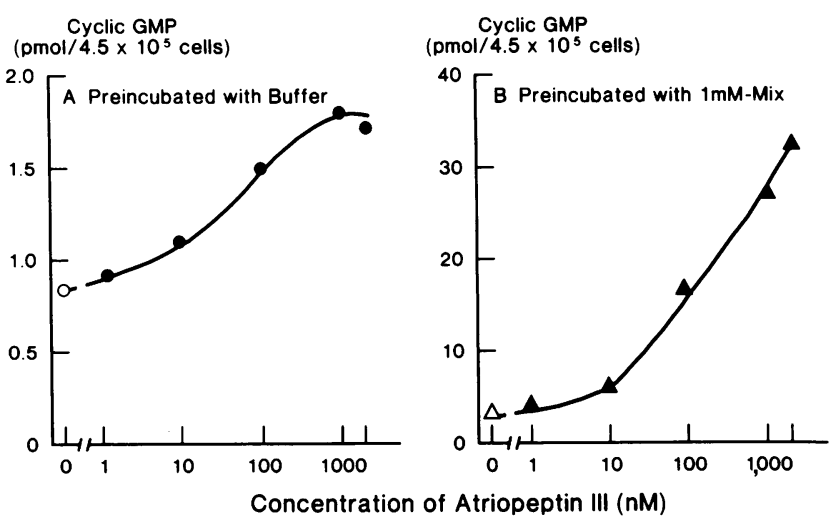

Figure 3. Effect of atriopeptin III on cyclic GMP accumulation in the $(A)$ absence and $(B)$ presence of MIX. Endothelial monolayers were preincubated at $37^{\circ} \mathrm{C}$ for 5 min with $475 \mu \mathrm{l}$ of $(A)$ Hanks'-Hepes buffer alone or $(B)$ Hanks'-Hepes buffer containing $1 \mathrm{mM}$ MIX. After the preincubation period, $25 \mu$ l of Hanks'-Hepes buffer alone or containing atriopeptin III (at an initial concentration 20-fold higher than the final concentration indicated) was added to the preincubation buffer and incubations were continued for $10 \mathrm{~min}$. Values are expressed as means of duplicate determinations; similar findings were obtained in two other experiments. The production of 6-keto-PGF ${ }_{1 \alpha}$ in monolayers preincubated with Hanks'-Hepes buffer followed by a 10-min incubation with increasing concentrations of atriopeptin III was as follows: control, $8 \pm 1 \mathrm{nM} ; 1 \mathrm{nM}$ atriopeptin III, $6 \pm 1 \mathrm{nM} ; 10$ $\mathrm{nM}$ atriopeptin III, $5 \pm 1 \mathrm{nM} ; 100 \mathrm{nM}$ atriopeptin III, $6 \pm 1 \mathrm{nM} ; 1,000$ $\mathrm{nM}$ atriopeptin III, $7 \pm 2 \mathrm{nM}$; and $2,000 \mathrm{nM}$ atriopeptin III, $5 \pm 1 \mathrm{nM}$.

centration of cyclic GMP alone is insufficient to induce $\mathrm{PGI}_{2}$ biosynthesis. It is also unlikely that cyclic GMP is directly involved in the regulation of $\mathbf{P G I}_{2}$ production, as preincubation of the endothelium with atriopeptin III, sodium nitroprusside, or tert-butylhydroperoxide had no effect on the subsequent

Table IV. Comparison of the Effect of A23187, tert-Butylhydroperoxide, and Sodium Nitroprusside on $P I_{2}$ Biosynthesis and Cyclic GMP Accumulation

\begin{tabular}{|c|c|c|c|}
\hline \multirow[b]{2}{*}{ Additions } & \multirow[b]{2}{*}{ 6-Keto-PGF ${ }_{1 a^{*}}$} & \multicolumn{2}{|c|}{$\begin{array}{l}\text { Cyclic GMP } \\
\text { (pmol/4.5 } \times 10^{5} \text { cells) }\end{array}$} \\
\hline & & Control & MIX (1 mM) \\
\hline & $n M$ & & \\
\hline None & $33 \pm 2$ & $0.92 \pm 0.03$ & $10.77 \pm 0.76$ \\
\hline A23187 (4 $\mu \mathrm{M})$ & $705 \pm 40$ & $2.10 \pm 0.26$ & $79.92 \pm 4.71$ \\
\hline $\begin{array}{l}\text { tert-Butylhydrop } \\
\quad(100 \mu \mathrm{M})\end{array}$ & $61 \pm 4$ & $1.43 \pm 0.14$ & $76.91 \pm 5.86$ \\
\hline $\begin{array}{l}\text { Sodium nitropru } \\
\qquad(1 \mathrm{mM})\end{array}$ & $38 \pm 5$ & $3.25 \pm 0.42$ & $91.32 \pm 5.53$ \\
\hline
\end{tabular}

Endothelial monolayers were preincubated at $37^{\circ} \mathrm{C}$ for $5 \mathrm{~min}$ with $475 \mu \mathrm{l}$ of Hanks'-Hepes buffer alone (controls) or Hanks'-Hepes buffer containing $1 \mathrm{mM}$ MIX. After the preincubation period, $25 \mu \mathrm{l}$ of Hanks'-Hepes buffer containing the test agent (at an initial concentration 20-fold higher than the final concentration) was added to the preincubation buffer and incubations were continued for $10 \mathrm{~min}$. All values are expressed as means \pm SEM of triplicate determinations; similar findings were obtained in two other experiments.

* 6-Keto-PGF ${ }_{1 \alpha}$ production in monolayers preincubated for $5 \mathrm{~min}$ with Hanks'-Hepes buffer followed by a 10-min incubation with the indicated addition. 


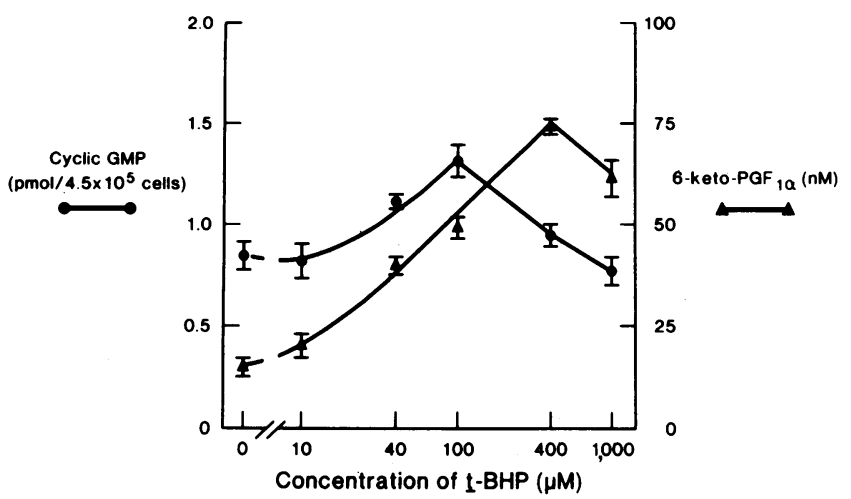

Figure 4. Effect of tert-butylhydroperoxide ( $t$-BHP) on cyclic GMP accumulation and $\mathbf{P G I}_{2}$ production. Endothelial monolayers were incubated for $5 \mathrm{~min}$ at $37^{\circ} \mathrm{C}$ with the concentration of $t$-BHP indicated. Values are expressed as means \pm SEM or triplicate determinations; similar findings were obtained in two other experiments.

stimulation of $\mathrm{PGI}_{2}$ biosynthesis by thrombin, $\mathrm{A} 23187$, or arachidonic acid (data not shown).

\section{Discussion}

The results of the present study demonstrate that receptor-mediated stimuli of $\mathrm{PGI}_{2}$ biosynthesis such as thrombin, bradykinin, and histamine, or the calcium ionophore A23187, stimulate cyclic GMP accumulation in primary monolayer cultures of human umbilical vein endothelium. A similar correlation, specifically, between the stimulation of phosphatidylinositol hydrolysis and cyclic GMP accumulation in response to activation of muscarinic-cholinergic, $\alpha$-adrenergic, histamine $\mathrm{H}_{1}$, bradykinin, angiotensin, and thrombin receptors, has previously been reported in a number of other cell types (for reviews see references 1-4, and reference 12). Although it has not yet been shown that phosphatidylinositol hydrolysis mediates the induction of $\mathrm{PGI}_{2}$ biosynthesis in endothelial cells, the observed increase in cyclic GMP provides indirect evidence suggesting that this pathway is likely to be involved.

Studies with the cyclic nucleotide phosphodiesterase inhibitor, MIX, show that increases in the intracellular concentration of cyclic GMP result from activation of guanylate cyclase and not from inhibition of cyclic GMP phosphodiesterase activity. At present, the mechanism by which physiologic stimuli mediate the activation of guanylate cyclase in intact cells is poorly understood. Although $\mathrm{Ca}^{2+}$ is required for full expression of guanylate cyclase activity in cell-free systems (13), it is not known whether $\mathrm{Ca}^{2+}$ is the primary mediator of hormonal activation of guanylate cyclase in intact cells (14). In some cell types, hormonally induced increases in cyclic GMP can be blocked by agents that interfere with the release or metabolism of unsaturated fatty acids $(15,16)$. On the basis of these and other studies that show that unsaturated fatty acids and fatty acid peroxides can activate guanylate cyclase directly (17), it has been concluded that these substances are the physiological activators of soluble guanylate cyclase in intact cells. However, evidence is given here that clearly shows that neither arachidonic acid nor its metabolites are involved in mediating the effects of stimulatory agonists with respect to activation of guanylate cyclase. First, exposure of endothelial monolayers to arachidonic acid had no effect on cyclic GMP accumulation either in the absence or presence of MIX, despite marked production of $\mathrm{PGI}_{2}$. Second, inhibition of cyclooxygenase activity with aspirin or ibuprofen had no effect on the stimulation of cyclic GMP accumulation observed in response to thrombin, bradykinin, histamine, or A23187. Third, inhibition of lipoxygenase and cyclooxygenase with ETYA had no effect on the stimulation of cyclic GMP accumulation by any of the agents tested. Fourth, inhibition of arachidonic acid release by quinacrine, presumably via inhibition of phospholipase $A_{2}$ activity, had no effect on increases in the intracellular concentration of cyclic GMP induced by any of the stimuli tested. These findings strongly support the view that activation of guanylate cyclase is not mediated by arachidonic acid or by its metabolites, which include products of cyclooxygenase activity such as prostaglandin endoperoxides, $\mathrm{PGI}_{2}$, and/or products of lipoxygenase activity such as 15 -hydroxyeicosatetraenoic acid.

The activation of guanylate cyclase must therefore be mediated by a factor generated by an initial step in the stimulusresponse coupling mechanism. Although it has not yet been established that extracellular signals stimulate $\mathrm{Ca}^{2+}$ mobilization via phosphatidylinositol hydrolysis in endothelial cells, it is clear that $\mathrm{Ca}^{2+}$ plays an important role in mediating the effects of these agents. It is therefore likely that $\mathrm{Ca}^{2+}$ is involved in the activation of guanylate cyclase in these cells. A central role for $\mathrm{Ca}^{2+}$ in the activation of guanylate cyclase is also suggested by the observation that the stimulatory effects of $A 23187$, and particularly of thrombin, on cyclic GMP accumulation are dependent on the presence of extracellular $\mathrm{Ca}^{2+}$. It is interesting to note that $\mathbf{P G I}_{2}$ production in response to thrombin, but not A23187, was unaffected by the absence of extracellular $\mathrm{Ca}^{2+}$. This observation suggests that different pools of $\mathrm{Ca}^{2+}$ are involved in mediating the effects of thrombin with respect to the biosynthesis of $\mathrm{PGI}_{2}$ and cyclic GMP. The interaction of thrombin with its putative receptor may simultaneously trigger the activation of two parallel pathways, one leading to $\mathrm{PGI}_{2}$ production and the other to cyclic GMP accumulation.

Examination of the time-courses and dose-response relationships of the effect of thrombin and A23187 suggests that a close, albeit undefined, relationship clearly exists between enhanced production of $\mathrm{PGI}_{2}$ and cyclic GMP accumulation. Significant increases in cyclic GMP were observed within $30 \mathrm{~s}$ of the addition of a stimulus to endothelial monolayers. Maximal increases in cyclic GMP, attained by $2 \mathrm{~min}$, slowly returned to baseline by $20 \mathrm{~min}$ in the presence of thrombin, histamine, and bradykinin, whereas they remained half-maximally elevated for at least $40 \mathrm{~min}$ in the presence of A23187. These findings suggest that guanylate cyclase is rapidly activated upon exposure of the endothelium to a stimulus, and that it remains in an activated state for a relatively long period of time. The induction of $\mathrm{PGI}_{2}$ biosynthesis also occurs very rapidly. Studies with the thrombin inhibitor DAPA (dansylarginine- $N$-(3-ethyl-1,5-pentanediyl)amide) (18), indicate that exposure of the endothelium to active thrombin for as little as $6 \mathrm{~s}$ is sufficient to induce maximal release of $\mathrm{PGI}_{2}$ (Brotherton, A. F. A., unpublished results). The concentration response relationships of each stimulus tested with respect to both $\mathrm{PGI}_{2}$ production and cyclic GMP production were also found to be nearly identical, with the exception that a somewhat lower concentration of each agent stimulated a significant increase in cyclic GMP without effect on $\mathrm{PGI}_{2}$ production.

Investigation of the effects of a number of agents known to increase cyclic GMP accumulation in other cell types provides evidence which suggests that an increase in the intracellular concentration of cyclic GMP does not, by itself, mediate the induc- 
tion of $\mathrm{PGI}_{2}$ biosynthesis in endothelial cells. Although significant increases in cyclic GMP were observed upon exposure of the endothelium to sodium nitroprusside or atriopeptin III, no increase in $\mathrm{PGI}_{2}$ production over baseline was observed. Since sodium nitroprusside and atriopeptin III have been shown to activate only the soluble (19) or particulate (20) forms of guanylate cyclase, respectively, it is reasonable to conclude that one or both of these agents increases cyclic GMP levels via the same mechanism as stimuli of $\mathrm{PGI}_{2}$ biosynthesis. Although tert-butylhydroperoxide had a small stimulatory effect on $\mathrm{PGI}_{2}$ production, it is unlikely that this effect is mediated by cyclic GMP, as higher concentrations of this agent stimulated larger increases in $\mathrm{PGI}_{2}$ without a concomitant effect on cyclic GMP accumulation. These findings argue against a primary role for cyclic GMP in mediating the induction of $\mathrm{PGI}_{2}$ biosynthesis in response to extracellular stimuli.

Even though a wide variety of hormones, regulatory substances, experimental conditions, and drugs have been reported to increase the intracellular concentration of cyclic GMP in an equally wide variety of intact tissue and cell preparations, the precise physiological role of this cyclic nucleotide remains a mystery. By analogy with cyclic AMP, it has been assumed that cyclic GMP functions as an intracellular messenger for at least some of the extracellular signals that affect cyclic GMP levels. However, in sharp contrast to the well-characterized cyclic AMP system, there are only a few cell types in which unequivocal effects of cyclic GMP have been demonstrated. Most notably, there is convincing evidence that cyclic GMP mediates relaxation of both vascular and nonvascular smooth muscle $(21,22)$, and that it plays a central role in the regulation of rod membrane voltage $(23,24)$. It has been suggested by Walter $(25)$ that difficulties encountered with establishing a clear-cut role for cyclic GMP may stem from a dogmatic adherence to the criteria developed by Sutherland et al. (26) for cyclic AMP. For example, the inability to correlate a hormone or drug-induced change in the cellular level of cyclic GMP with the physiological effect produced by these agents, or the inability to mimic the hormone or drug-induced physiological effect by extracellular application of cyclic GMP or cyclic GMP analogues, may in fact be attributable to the likelihood that the induction of the effect involves several second messengers. In such a case, $\mathrm{Ca}^{2+}$ may function as the primary intracellular messenger, while cyclic GMP may have an important, albeit subtle, role in the short- or perhaps long-term modulation of the response. Experimentally, it would be difficult to mimic the action of cyclic GMP solely by manipulating the intracellular concentration of the cyclic nucleotide or by the addition of analogues if it acts to modulate the effects of the primary intracellular messenger. These experimental problems are further confounded by the limited understanding of the effector mechanisms of cyclic GMP in intact, physiologically responsive cells.

In light of the above considerations, full appreciation and interpretation of the results of the present study must await further investigation of the mechanism of action of cyclic GMP in these cells. Results of preliminary studies indicate that thrombin and A23187 stimulate specific protein phosphorylation in intact primary human umbilical vein endothelium (27); studies are currently in progress to determine whether cyclic GMP mediates this response.

Although it is clear that cyclic GMP does not, by itself, mediate the induction of $\mathrm{PGI}_{2}$ biosynthesis in the endothelium, it may have an important role in modulating this response. For example, it is possible that cyclic GMP is involved in mediating the reuptake of $\mathrm{Ca}^{2+}$ into intracellular stores. Alternatively, increases in the intracellular concentration of cyclic GMP that occur as a result of the induction of $\mathrm{PGI}_{2}$ biosynthesis by extracellular stimuli may, by some mechanism, trigger the synthesis of cyclooxygenase. This latter possibility is particularly intriguing as we have shown that this enzyme is rapidly deactivated as a result of $\mathrm{PGI}_{2}$ biosynthesis (28).

At present, the only other well-described cell culture system available for investigation of physiological role of cyclic GMP is the murine neuroblastoma clone N1E-115. These cells were originally derived from a neuroblastoma and are reported to display many of the characteristic properties of normal differentiated neurons (29). Although the stimulation of neurotransmitter receptors on these cells by muscarinic or histamine $\mathbf{H}_{1}$ agonists, bradykinin, or thrombin, has been shown to cause rapid and transient increases in cyclic GMP that are dependent on the presence of extracellular $\mathrm{Ca}^{2+}(29,30)$, the role of cyclic GMP in mediating or modulating the effects of these agents is not known. In sharp contrast to the findings of the present study, it has been suggested (30) that increases in cyclic GMP formation observed in response to stimulation of neurotransmitter receptors involves the release of arachidonic acid, and that an oxidative metabolite of this fatty acid stimulates soluble guanylate cyclase activity.

For many reasons, primary monolayer cultures of human umbilical vein endothelium provide an ideal model system for investigation of the role of cyclic GMP in signal transduction. Most importantly, these cells represent a homogeneous population of normal, untransformed human cells that are responsive to a wide variety of agents, exhibit numerous, well-described properties and physiologic responses, and are easy to grow. In addition, as the results of the present study show, the induction of $\mathrm{PGI}_{2}$ biosynthesis is closely associated with cyclic GMP accumulation; and, the activation of guanylate cyclase is mediated by a factor or factors generated by an initial step in the stimulusresponse coupling mechanism and not by oxidative metabolites of arachidonic acid. The marked and relatively prolonged activation of guanylate cyclase, which results in the maintenance of a significant, net increase in the intracellular concentration of cyclic GMP for several minutes, may ultimately provide insight as to the mechanism of action of cyclic GMP in these cells. Lastly, we have found (31) that early passage (1st through 3rd) of primary cultures of human umbilical vein endothelium results in a progressive, parallel loss of the capacity of these cells to produce $\mathrm{PGI}_{2}$ or to synthesize cyclic GMP in response to extracellular stimuli. As these passaged cells retain all other characteristic morphologic and physiologic properties of primary endothelial cultures (32), it is clear that the co-availability of physiologically responsive (i.e., with respect to $\mathrm{PGI}_{2}$ and cyclic GMP biosynthesis) and progressively nonresponsive populations of the same cell type provides a unique opportunity to examine the factors involved in the expression of stimulus-response coupling mechanisms as well as the regulatory role of cyclic GMP.

\section{Acknowledgments}

The author wishes to thank Christie R. Clark for excellent technical assistance, Connie Schroeder for preparation of the cell cultures, and Donna Heisdorffer for typing the manuscript.

This work was supported, in part, by grants HL-14320 (Specialized 
Center of Research in Atherosclerosis) and grant 84-G-2 from the Iowa Heart Association.

\section{References}

1. Berridge, M. J., and R. F. Irvine. 1984. Inositol trisphosphate, a novel second messenger in cellular signal transduction. Nature (Lond.). 312:315-321.

2. Rasmussen, H., I. Kojima, K. Kojima, W. Zawalich, and W. Apfeldorf. 1984. Calcium as intracellular messenger. sensitivity modulation, C-kinase pathway, and sustained cellular response. Adv. Cyclic Nucleotide Protein Phosphorylation Res. 18:159-193.

3. Nishizuka, Y. 1984. The role of protein kinase $C$ in cell surface signal transduction and tumor promotion. Nature (Lond.). 308:693-698.

4. Nishizuka, Y. 1984. Turnover of inositol phospholipids and signal transduction. Science (Wash. DC). 225:1365-1370.

5. Levin, R. I., B. B. Weksler, A. J. Marcus, and E. A. Jaffe. 1984. Prostacyclin production by endothelial cells. In Biology of Endothelial Cells. E. A. Jaffe, editor. Martinus Nijhoff, Boston. 228-247.

6. Brotherton, A. F. A., D. E. Macfarlane, and J. C. Hoak. 1982. Prostacyclin biosynthesis in vascular endothelium is not inhibited by cyclic AMP. Studies with 3-isobutyl-1-methylxanthine and forskolin. Thromb. Res. 28:637-647.

7. Weksler, B. B., C. W. Ley, and E. A. Jaffe. 1978. Stimulation of endothelial cell prostacyclin production by thrombin, trypsin, and ionophore A23187. J. Clin. Invest. 62:923-930.

8. Brotherton, A. F. A., and J. C. Hoak. 1982. Role of $\mathrm{Ca}^{2+}$ and cyclic AMP in the regulation of the production of prostacyclin by the vascular endothelium. Proc. Natl. Acad. Sci. USA. 74:495-499.

9. Henriksen, R. A., W. G. Owen, M. E. Nesheim, and K. A. Mann. 1980. Identification of a congenital dysthrombin, Thrombin Quick. $J$. Clin. Invest. 66:934-440.

10. Jaffe, E. A., R. L. Nachman, C. G. Becker, and C. R. Minick. 1973. Culture of human endothelial cells derived from umbilical veins. Identification by morphologic and immunologic criteria. J. Clin. Invest. 52:2745-2756.

11. Czervionke, R. L., J. C. Hoak, and G. L. Fry. 1978. Effect of aspirin on thrombin-induced adherence of platelets to cultured cells from the blood vessel wall. J. Clin. Invest. 62:847-856.

12. Michell, R. H. 1975. Inositol phospholipids and cell surface receptor function. Biochim. Biophys. Acta. 415:81-147.

13. Schultz, G., J. G. Hardman, K. Schultz, C. E. Baird, and E. W. Sutherland. 1973. The importance of calcium ions for the regulation of guanosine 3':5' cyclic monophosphate levels. Proc. Natl. Acad. Sci. USA. 70:3889-3893.

14. Ohsako, S., and T. Deguchi. 1984. Receptor-mediated regulation of calcium mobilization and cyclic GMP synthesis in neuroblastoma cells. Biochem. Biophys. Res. Commun. 122:333-339.

15. Spies, C., D.-K. Schultz, and G. Schultz. 1980. Inhibitory effects of mepacrine and eicosatetraynoic acid on cyclic GMP elevations caused by calcium and hormonal factors in rat ductus deferens. Nauyn-Schmiedebergs Arch. Pharmacol. 311:71-77.

16. Snider, R. M., M. McKinney, C. Forray, and E. Richelson. 1984. Neurotransmitter receptors mediate cyclic GMP formation by involvement of arachidonic acid and lipoxygenase. Proc. Natl. Acad. Sci. USA. 81:3905-3909.
17. Graff, G., J. H. Stephenson, D. B. Glass, M. K. Haddox, and N. D. Goldberg. 1978. Activation of soluble splenic cell guanylate cyclase by prostaglandin endoperoxides and fatty acid hydroperoxides. J. Biol. Chem. 253:7662-7676.

18. Nesheim, M. E., F. G. Prendergast, and K. G. Mann. 1979. Interactions of a fluorescent active-site-directed inhibitor of thrombin: dansylarginine N-(3-ethyl-1,5-pentanediyl)amide. Biochemistry. 18:9961003.

19. Winquist, R. J., E. P. Faison, S. A. Waldman, K. Schwartz, F. Murad, and R. M. Rapoport. Atrial natriuretic factor elicits an endothelium-independent relaxation and activates particulate guanylate cyclase in vascular smooth muscle. Proc. Natl. Acad. Sci. USA. 81:76617664.

20. Waldman, S. A., R. M. Rapoport, and F. Murad. 1984. Atrial natriuretic factor selectivity activates particulate guanylate cyclase and elevates cyclic GMP in rat tissues. J. Biol. Chem. 259:14332-14334.

21. Rapoport, R. M., and F. Murad. 1983. Endothelium dependent and nitrovasodilator-induced relaxation of vascular smooth muscle: role of cyclic GMP. J. Cyclic Nucleotide Protein Phosphorylation Res. 9:281296.

22. Lincoln, T. M., and R. M. Johnson. 1984. Possible role of cyclic GMP-dependent protein kinase in vascular smooth muscle function. Adv. Cyclic Nucleotide Protein Phosphorylation Res. 17:285-296.

23. George, J. S., and W. A. Hagins. 1983. Control of $\mathrm{Ca}^{2+}$ in rod outer segment disks by light and cyclic GMP. Nature (Lond.). 303:344348.

24. Bitensky, M. W., A. Yamazaki, M. A. Wheeler, V. S. George, and M. M. Rasemick. 1984. The mechanism of activation of light-activated phosphodiesterase and evidence for homology with hormoneactivated adenylate cyclase. Adv. Cyclic Nucleotide Protein Phosphorylation Res. 17:227-237.

25. Walter, U. 1984. Cyclic GMP-regulated enzymes and their possible physiological functions. Adv. Cyclic Nucleotide Protein Phosphorylation Res. 17:249-257.

26. Robison, G. A., R. W. Butcher, and E. W. Sutherland. 1971. Cyclic AMP. Academic Press, Inc., New York.

27. Brotherton, A. F. A. 1985. Thrombin and A23187 induce specific protein phosphorylation in intact cultured endothelium. Fed. Proc. 44: 1843A. (Abstr.)

28. Brotherton, A. F. A., and J. C. Hoak. 1983. Prostacyclin biosynthesis in cultured vascular endothelium is limited by deactivation of cyclooxygenase. J. Clin. Invest. 72:1255-1261.

29. Snider, R. M., M. McKinney, J. W. Fenton II, and E. Richelson. 1984. Activation of cyclic nucleotide formation in murine neuroblastoma NIE-115 cells by modified human thrombins. J. Biol. Chem. 259:90789081.

30. Snider, R. M., M. McKinney, C. Forray, and E. Richelson. 1984. Neurotransmitter receptors mediate cyclic GMP formation by involvement of arachidonic acid and lipoxygenase. Proc. Natl. Acad. Sci. USA. 81:3905-3909.

31. Brotherton, A. F. A. 1984. Passage of primary human umbilical vein endothelium results in the loss of stimulus-response coupling. Clin. Res. 32:305A. (Abstr.)

32. Fry, G., T. Parsons, J. Hoak, H. Sage, R. D. Gingrich, L. Ercolani, D. Ngheim, and R. Czervionke. 1984. Properties of cultured endothelium from adult human vessels. Arteriosclerosis. 4:4-13. 